Revista electrónica de difusión científica - Universidad Sergio Arboleda Bogotá - Colombia

http://www.usergioarboleda.edu.co/civilizar Reservados todos los derechos de autor Enero 2004

\title{
FUNDAMENTO DE LA LEGITIMIDAD FRENTE AL ÁMBITO CULTURAL
}

\author{
Juan Pablo Suárez Orozco ${ }^{1}$
}

RESUMEN:

El fundamento de la legitimidad del poder político varía según el ámbito cultural de cada sociedad. Las razones para que una cultura o grupo consienta al poder, responden a circuntacias propias, y esto hace que las motivaciones de la obediencia política no tengan por que coincidir con las de otros conglomerados sociales.

\section{ABSTRACT:}

Every social system has its own idea on the basis of power legitimacy. The reasons to accept power structures depend on specific circumstances; and then the reasons, of political obedience in a determinas ¿ted society not necessary are the same of all others.

PALABRAS CLAVE: Legitimidad, poder, ámbito cultural.

[...] Una de las características de los pueblos indígenas consiste en que, a diferencia de las comunidades campesinas, aquéllos pueden no reconocer o no apreciar la soberanía que el Estado ejerce sobre ellos. Los campesinos, en cambio, se ven así mismos como miembros de la sociedad nacional (Goodland, 1980). Ello se debe en parte a que las instituiciones políticas, sociales y religiosas de los pueblos indígenas son anteriores al surgimiento -en el siglo XIX- de Estados nacionales como Colombia y Venezuela. Por la razón anterior, la legitimidad de las instituciones de tipo coercitivo, como la Policía, la Guardia Nacional y otros cuerpos armados, es cuestionada cuando éstas tienen alguna injerencia en enfrentamientos de tipo intraetnico en el territorio guajiro. $>>^{2}$

SUMARIO: 1 . Introducción.

2. Imposición de los fundamentos de la legitimidad de una cultura a otra.

3. El ámbito cultural fundamenta la legitimidad

4. La legitimidad del poder político del Estado frente a sus ámbitos culturales internos.

${ }^{1}$ Abogado, docente e investigador, de la Universidad de la Sergio Arboleda, BogotáColombia. Especialista en Derecho Comercial de la Universidad Javeriana, BogotáColombia. Magíster en Administración de Empresas (MBA) de Baldwin-Wallace College, Cleveland-Ohio-USA. Candidato a doctor en Derecho de la Universidad Alfonso X el Sabio, Madrid-España.

2 GUERRA CURVELO, WEILDER, La Disputa y la Palabra, La ley en la Sociedad Wayuu, Premios Nacionales de Cultura, Ministerio de Cultura, Bogotá, 2002, página 197 
5. Conclusión.

6. Bibliografía consultada.

\section{Introducción}

El consentimiento al poder ha sido considerado como una condición esencial para que las relaciones de mando y de obediencia en un Estado se desenvuelvan armónicamente. Vladimiro Naranjo Mesa anota que "En nuestra época actual la idea más comúnmente admitida, al menos dentro del mundo occidental, es aquella que ve en la convergencia de las aspiraciones del grupo y de los objetivos del poder, el fundamento de la legitimidad de este."3

Las razones que llevan a ese consenso pueden ser diversas y varía según las circunstancias propias de cada sociedad. La obediencia política en una cultura estará cimentada en consideraciones particulares, que no tiene que coincidir con las asumidas por otros pueblos. En algunos casos serán las creencias religiosas las que fundamenten la legitimidad del poder, mientras que en otros la percepción del mundo, desde el punto de vista individual o colectivo, o la concepción económica que se tenga del funcionamiento de los mercados, por ejemplo, constituirán las motivaciones para consentir al poder político.

Ese marco relativo a cada ámbito cultural, en donde nacen los criterios de validez del poder de cada sociedad, es precisamente el contexto dentro del cual se desarrollará la reflexión objeto del presente documento. Se expondrán ideas referentes a la imposición de los fundamentos de la legitimidad de una cultura a otra, al ámbito cultural como fundamento de la legitimidad y la legitimidad del poder político del Estado frente a sus ámbitos culturales internos.

\section{Imposición de los fundamentos de la legitimidad de una cultura a otra}

Ver las cosas, únicamente, desde el ámbito cultural al que se pertenece, puede llevar a pensar que sólo las ideas, valores y conductas, allí nacidos,

${ }^{3}$ NARANJO MESA, VLADIMIRO, Teoría constitucional e Instituciones Políticas, Editorial temis, Bogotá, 2003, página 123 
gozan de veracidad y validez. Por esa razón, algunas veces, cada cultura considera, por ejemplo, legítimo el sistema político dentro del cual se desarrolla. De esa forma, se le da, con ligereza, universalidad a los principios democráticos de una sociedad; lo que se acompaña de la pretensión de tornarlos organizadores políticos, absolutos, para todas las sociedades.

Se olvidan otras realidades políticas existentes, que han sido construidas y modificas por el ser humano, cuya conducta varía según las condiciones espaciales y temporales en las que se realice.

Dentro de ese contexto, se pretende extender los fundamentos de la legitimidad política que cada comunidad ha elaborado, a otras culturas que poseen razones propias y distintas a las de otras sociedades, para obedecer al poder que rige a sus miembros. Y aunque, en términos generales, se pueda definir la legitimidad en torno al consenso en el que debe descansar la comunidad política para aceptar pacíficamente un orden, no puede ello traducirse en unanimidad de todas las culturas sobre las razones de ese consentimiento. En otras palabras, la legitimidad puede ser una, pero las razones en que se fundamenta cambian, ${ }^{4}$ de acuerdo con la concepción cultural y antropológica de cada sociedad.

Esta concepción acerca de que unos sistemas políticos, económicos, religiosos, etc., son mejores que otros, y que por ello deben ser, más que

${ }^{4} \mathrm{Al}$ respecto, el profesor ELOY GARCÍA formula y responde la siguiente pregunta: «¿Cuál es la razón que lleva a un hombre a acatar la voluntad de otro hombre? No cabe una respuesta de valor universal: la respuesta la da en cada momento la realidad en que el hombre se halla inmerso, la idea de política -en el sentido amplio del término- que en cada sociedad prevalece, el grado de maduración de su conciencia colectiva, lo que significa que la obediencia nace de la aceptación social. Pero no existe un principio de obediencia al margen de la historia, como tampoco una razón única de la obediencia. Toda época construye la suya propia sobre su particular principio: la tradición, la religión, la legitimidad... La legitimidad es una particular forma de obediencia que se afirma cuando el consentimiento de los gobernados hacia el gobernante permite conjurar el recurso al miedo. La legitimidad supone la aceptación del Poder desde la misma sociedad llamada a la obediencia en a base en categorías socialmente autónomas, en principios surgidos de la propia realidad del Poder. La legitimidad, como tal, es la expresión de la racionalidad que desde sus orígenes ha venido caracterizando a la modernidad política...» (El Estado Constitucional ante su $<<$ Momento Maquiavélico $>>$, Cuadernos Civitas, Madrid, 2000, página 24) 
adoptados, implantados en otras culturas sin importar las consecuencias reales, es explicada por Amy L. Chua, profesora en la facultad de derecho de la Universidad de Yale. Ella ha desarrollado una teoría interesante ${ }^{5}$ - la cual aquí simplemente se expone, sin tomar partido alguno - sobre las consecuencias catastróficas que puede generar la implantación acelerada de las ideas democráticas y de libre mercado en los países en vía de desarrollo. (Lo que tradicionalmente ha sido considerado como un estímulo para las economías de los países pobres y para la promoción de la paz). Esa filosofía occidental de la globalización, particularmente estadounidense, solo beneficia a las minorías dominantes - especialmente grupos étnicos impopulares - en los países menos desarrollados, las cuales ejercen el control desproporcionado de los recursos económicos, y por consiguiente el dominio sobre las descontentas etnias mayoritarias. La doctora Chua cita los siguientes ejemplos: chinos en el Sudeste Asiático (en las Filipinas, por ejemplo, el $1 \%$ de la población China controla el $60 \%$ de la economía privada); indios en África Oriental; libaneses en África Occidental; ibos en Nigeria; bamilekes en Camerún; tutsis en Rwanda; kikuyos en Kenia; blancos en Sudáfrica y Zimbabwe; croatas en la antigua Yugoslavia; judíos en Rusia; tamils en Sri Lanka, etc. Las razones para que esas minorías ostenten el dominio, sobre todo de los mercados, son diferentes, y van desde la competencia empresarial, la historia del apartheid, hasta la opresión colonial, etc. ${ }^{6}$

No obstante, Chua no es enemiga ni de la globalización ni de la democracia. Al contrario, cree que en algunas de sus bondades. Pero lo que

${ }^{5}$ CHUA, AMY L., WORLD ON FIRE: How Exporting Free Market Democracy Breeds Ethnic Hatred and Global Instability, Doubleday, 2003

${ }^{6}$ En esa situación, según Amy L. Chua, los mercados y la democracia se orientan a favorecer a los grupos étnicos dominantes, cuya riqueza aumenta desproporcionadamente frente a la mayoría en las que se genera envidia y resentimiento. El rico no solo es visto como rico, sino como un advenedizo. Esto es aprovechado por los políticos, quienes ven aquí una oportunidad para ganar votos, alimentado el odio de las mayorías étnicas contra las minorías dominantes. El resultado es una situación de conflicto étnico que conduce a una de las siguientes reacciones: 1) Reacción contra el mercado (ejemplo: a través de la persecución étnica y confiscación o nacionalización de los bienes de la minoría) 2) Reacción contra la democracia proveniente de las fuerzas que respaldan a las minorías dominantes (ejemplo: a través de los amigos o aliados capitalistas) o 3) Una violenta reacción directamente contra las minorías dominantes (ejemplo: a través de la expulsión o limpieza étnica). 
sÍ crítica es la idea estadounidense de exportar su cultura política a países en desarrollo, en donde pretende implantarla rápidamente, sin considerar si hay aceptación o no por parte de los destinatarios.

\section{El ámbito cultural fundamenta la legitimidad}

El modo de ser de cada pueblo estructura las razones sobre las cuales los gobernados aceptan el poder. De allí que la justificación del consentimiento hacia los gobernantes varíe de una cultura a otra. Habrá sociedades, por ejemplo, que consideren legítimo su sistema político por razones históricas; para otras los motivos del consenso en torno al poder político lo constituirá el factor religioso; mientras que para otras la concepción económica fundamenta la aceptación de quienes gobiernan.

En este contexto resulta oportuno traer a colación la investigación realizada por Terence Brake, Danielle Medina Walter y Thomas (Tim) Walter $^{7}$, que a pesar de ser un estudio aplicado a los negocios internacionales, tiene gran utilidad en el análisis de la legitimidad frente a cada ámbito cultural. Ellos crearon un modelo sobre las orientaciones culturales de seis regiones en el mundo: África, Asia, América Latina, Europa, Medio Oriente y Norte América, basados en diez variables: (y 36 orientaciones relevantes sobre esas variables) medio ambiente, tiempo, acción, comunicación, espacio, poder, individualismo, competitividad, estructura y forma de pensar. ${ }^{8}$ Para estos investigadores ese modelo constituye una herramienta importante para aquellos interesados en hacer negocios internacionales, en los cuales es fundamental, para triunfar, conocer las diferencias culturales.

Así por ejemplo, sobre la variable poder se hace la interpretación de las orientaciones que cada cultura tiene respecto de la jerarquía ${ }^{9}$ y la igualdad. ${ }^{10}$

7 BRAKE, TERENCE; MEDINA WALTER, DANIELLE; WALTER THOMAS (TIM), Doing Business INTERNATIONALLY, The Guide to Cross-Cultural Success, Edit. McGraw-Hill, New York, San Francisco, Washington D.C, Auckland, Bogotá, Caracas, Lisbon, London, Madrid, Mexico City, Milan, Montreal, New Delhi, San Juan, Singapore, Sydney, Tokio, Toronto, 1995

8 BRAKE, TERENCE; MEDINA WALTER, DANIELLE; WALTER THOMAS (TIM), Op cit., Figura 2-4 y tabla 2-2 del libro, páginas 45, 46 y 47

9 <<Jerarquía. Las culturas jerárquicas dicen cosa como: “Ocupa tu lugar”, "No molestes al jefe”, Respeta a tus mayores”. El poder y la jerarquía son centralizados, y la 
estructura organizacional -en términos de niveles altamente demarcados- estrictamente controlada. Se espera que los gerentes se comporten de tal manera que refuercen su estatus. Por ejemplo, si un gerente americano que tiende a la informalidad, llega a México y reúne a su personal, pronto se dará cuenta que tendrá problemas de credibilidad por parte de sus subalternos. El jefe es el jefe. El respeto por su posición es vital para mantener las operaciones de la compañía.

Knud Cristensen, gerente de personal de Dinamarca en BP (British Petroleum) Oil Europe, explica que “la compañía promueve la 'retroalimentación' sobre las opiniones que los gerentes hacen acerca de la labor de jefes”. Eso funciona bien en Escandinava, Gran Bretaña y Holanda, en donde la tendencia es que los gerentes no sena intimidados por sus superiores. Pero es más difícil en Francia, Turquía y Grecia, en donde la tradición se inclina hacia es el respeto de la autoridad. Los gerentes en esos países podrían ser menos directos, al opinar sobre sus jefes en un ejercicio de retroalimentación.

La planeación en esas culturas es autocrática y paternalista. En general, los gerentes toma decisiones sin consultar a los niveles inferiores, el trabajo no se salta el conducto regular de la organización, los empleados esperan que los gerentes tomen la iniciativa para el trabajo subordinado..., y los planes serán implementados de acuerdo con los deseos del gerente....Cualquier negociación con las culturas jerárquicas necesita exigir respecto con el título y el status apropiado.

Las culturas árabes, la mayoría de las latinoamericanas y las asiáticas tienen mayor tolerancia la jerarquía que las culturas occidentales. Las excepciones latinoamericanas incluyen a Argentina y Costa Rica, las cuales han sido influenciadas por las culturas anglosajona y europea. Dentro de la misma Europa, Francia, Bélgica, España y Turquía también demuestran gran tolerancia a la jerarquía. Una de nuestras clientes en una compañía de telecomunicaciones organizó una conferencia para la región de América. Para introducir la conferencia, ella planeó un evento social para todos los niveles (desde las secretarias hasta el director), con el fin de ayudar estimular trabajo en equipo. Fue un fracaso, debido al boicot promovido por la oficina en México. Todos los niveles se sintieron insultados;..>> (BRAKE, TERENCE; MEDINA WALTER, DANIELLE; WALTER THOMAS (TIM), Op cit., páginas 62 y 63.)

$10<$ < Igualdad. En las culturas igualitarias, la desigualdad es considerada como una condición insatisfactoria, y se hacen esfuerzos para minimizarla a través de medios políticos y legales. La organización tiende a ser más plana, y el poder es descentralizado; la estructura organizacional apunta a estimular la autonomía y la responsabilidad individuales. En general, los empleados en las culturas igualitarias no aceptan que los gerentes gocen del derecho automático a tener más poder y privilegios; los cuales se deben ganar y, hasta cierto punto, compartidos. El gerente es visto como una figura a quien se le consulta, más que una figura de autoridad. Muchos empleados en las culturas igualitarias prefieren la autoridad impersonal de acuerdos mutuos sobre metas y objetivos, a un poder arbitrario de un superior. Para lograr que las cosas se hagan, el trabajo se puede saltar el los niveles de jerarquía de la organización, y a los empleados se les dan gran flexibilidad para implementar planes y desarrollar sus tareas. La delegación es un medio importante para lograr que realicen las labores, y para que el desarrollo de los empleados alcance su potencial. El desacuerdo con los gerentes es muy común, y se espera que los empleados 
Para las culturas con orientación jerárquica, el poder y la autoridad son centralizados y la estructura organizacional es supremamente controlada. El respeto por los superiores es vital en las relaciones interpersonales. Las decisiones son tomadas desde los altos niveles, de una manera autocrática y paternalista. Dentro estas culturas estarían las árabes, latinoamericanas y asiáticas.

De otro lado, para las culturas con orientación igualitaria frente al poder, los medios políticos y legales son puestos en marcha para disminuir las desigualdades, que son vistas como una insatisfactoria condición. El poder se descentraliza, y ello se refleja en la estructura organizacional que tiende a ser "plana”, en donde al individuo se le atribuye mayor autonomía y responsabilidad. Ejemplo de estás cultura se dá en los Estados Unidos, Reino Unido, Australia y Canadá.

El modelo planteado lleva consigo el peligro que genera toda generalización. Encasillar a una persona en modelos rígidos, en tipos de conductas, es olvidar la mutabilidad del comportamiento del hombre: El deseo, la inclinación o el pensamiento de hoy, no tiene que ser el de mañana. El ser humano tiene la capacidad de autodeterminarse. De tal manera que viviendo en cierto país puede comportarse en la forma como lo hace el grupo donde se desenvuelve, pues es potencialmente adaptable. Por el contrario, puede adoptar una conducta total o parcialmente contraria a la tradición de esa sociedad, precisamente por su capacidad para innovar, por su libertad de actuar o simplemente por inclinaciones caprichosas. Sin embargo, Brake, Medina y Walter aclaran que es importante tener en cuenta que [...] las generalizaciones son un importante punto de partida en cualquier clase de estudio; es difícil pensar en cualquier campo de investigación que no dependa de la generalización. Pero en el campo de los estudios transculturales, las generalizaciones se tornas destructiva cuando degeneran en estereotipos. Las generalizaciones están abiertas a la revisión y al cambio; los estereotipos son sistemas de creencias cerrados.

tengan iniciativa. La participación en la toma de decisiones es frecuentemente estimulada, así como también las consultas entre los niveles en la organización.

Dentro de las culturas que valoran la igualdad se encuentran los Estados Unidos, y otros países anglosajones como el Reino Unidos, Australia y Canadá.>> (BRAKE, TERENCE; MEDINA WALTER, DANIELLE; WALTER THOMAS (TIM), Op cit., página 63.) 
No importa que se presente nueva información, los estereotipos la canalizan dentro de categorías preexistentes (negativas o positivas). $>>{ }^{11}$ En su sentir, el modelo no pretende hacer estereotipos de la generalización, simplemente creen en la necesidad de generalizar al desarrollar cualquier investigación.

No obstante, el trabajo de estos investigadores, si puede tener alguna utilidad al buscar el fundamento de la legitimidad del poder político en cada cultura. No tanto por que se pueda concluir que los latinoamericanos, por ejemplo, dan aceptación a sus gobernantes por ser culturalmente jerárquicos o igualitarios, sino porque sí permite ver que cada cultura es diferente y que su grado y las razones de obediencia al poder político son propias y particulares y no iguales a otras, o a lo sumo similares.

\section{La Legitimidad del poder político del Estado frente a sus ámbitos culturales internos}

Pareciera que todo lo hasta aquí dicho hiciera alusión, únicamente, a la legitimidad de un Estado en referencia a ámbitos culturales externos. Sin embargo, lo que al respecto se ha sostenido tiene aplicación a la legitimidad del poder político estatal, en consideración a las diferentes culturas que pueden coexistir dentro del territorio de un Estado.

Para que un gobernante obtenga el consentimiento de los gobernados, sus decisiones han de consultar las formas de ser, pensar, sentir y actuar de las distintas culturas que conforman la población que gobierna. El reconocimiento y respeto de la diversidad cultural de un Estado fundamenta su legitimidad.

En Colombia se han hecho considerables esfuerzos, aunque no suficientes, para proteger la diversidad étnica y cultural de la nación. La Constitución de 1991 hizo un trascendental avance en la materia, con la consagración de las siguientes disposiciones:

Artículo 7. El Estado reconoce y protege la diversidad étnica y cultural de la Nación colombiana.

11 BRAKE, TERENCE; MEDINA WALTER, DANIELLE; WALTER THOMAS (TIM), Op cit., Figura 2-4 y tabla 2-2 del libro, páginas 44 y 45 
Art. 10: El castellano es el idioma oficial de Colombia. Las lenguas $y$ dialectos de los grupos étnicos son también oficiales en sus territorios. La enseñanza que se imparta en las comunidades con tradiciones lingüísticas propias será bilingüe.

Artículo 246: Las autoridades de los pueblos indígenas podrán ejercer funciones dentro de su ámbito territorial, de conformidad con sus propias normas y procedimientos, siempre que no sean contrarios a la Constitución y leyes de la República. La ley establecerá las formas de coordinación de esa jurisdicción especial con el sistema judicial nacional.

Artículo 286: Son entidades territoriales los departamentos, los distritos, los municipios y los territorios indígenas.

A pesar de que ese marco constitucional puede parecerle a algunos un gran logro jurídico, para otros, por el contrario, representa una pérdida de poder de los grupos étnicos. Este sentir es expuesto por el antropólogo colombiano Weilder Guerra Curvelo, en su estudio realzado sobre la ley de la sociedad Wayuu: ${ }^{12}$ [...] Las conquistas sociales obtenidas por los pueblos amerindios a través de reformas constitucionales pueden verse también, desde una perspectiva menos eufórica, como un proceso de legitimación del Estado frente a dichos pueblos y de validación de la dominación política que aquellos ejercen sobre éstos. La capacidad de intervención de los Estados en el seno de la vida social de los grupos indígenas, a través de disposiciones legislativas y administrativas que desarrollan las conquistas alcanzadas, aumentan en la medida en que se obtienen mayores logros jurídicos, logros que buscan, precisamente, una mayor autonomía en dichas agrupaciones humanas.>>

\section{Conclusión}

Conocer el ámbito cultural de cada pueblo puede permitir entender los fundamentos de la legitimidad en cada sociedad. Cuando un grupo social se percibe diferente culturalmente a otro y entiende que éste es distinto, ni

${ }^{12}$ GUERRA CURVELO, WEILDER, Op Cit., páginas 207 y 208 
superior ni inferior, y como tal debe ser tratado, se abre la posibilidad de que el respeto sea siempre la base de las relaciones interculturales.

Sí cada pueblo conociera y entendiera además de su propio ámbito cultural, la forma de ser de otras sociedades, tal vez sería más fácil aceptar y respetar las razones de la obediencia política de cada entorno social, lo cual podría conducir a la no imposición de las ideas de una cultura política a otra.

Igualmente, en las sociedades con diversidad étnica y cultural debe existir un verdadero consenso político que dé soporte legítimo al propio Estado. Las decisiones deben fundarse en el respeto a la autonomía cultural, para lograr la convergencia en el bien común y sea posible obtener el consentimiento real y no la imposición. [...] Consentir es aceptar; - sostiene Burdeau $^{13}$ - no es dominar, sino admitir la legitimidad de la dominación; no es tener el manejo de una actividad, sino reconocer el bien fundado en sus fines y la oportunidad de sus medios. En definitiva, es la duración del poder en la paz lo que constituye el más claro testimonio de aquello que es tenido como legitimo. $>>$

\section{Bibliografía Consultada}

BERTÍN, HUGO D., y CORBETA, JUAN CARLOS, La Noción de Legitimidad en el Concepto de los Político de Carl Schmitt, Editorial Struhart \& Cia., Buenos Aires, 1997

BRAKE, TERENCE; MEDINA WALTER, DANIELLE; WALTER THOMAS (TIM), Doing Business INTERNATIONALLY, The Guide to Cross-Cultural Success, Edit. McGraw-Hill, New York, San Francisco, Washington D.C, Auckland, Bogotá, Caracas, Lisbon, London, Madrid, Mexico City, Milan, Montreal, New Delhi, San Juan, Singapore, Sydney, Tokio, Toronto, 1995

CHUA, AMY L., WORLD ON FIRE: How Exporting Free Market Democracy Breeds Ethnic Hatred and Global Instability, Doubleday, 2003

GABALDÓN, LUIS GERARDO y otros, Legitimidad y Sociedad, Alfadil Ediciones, Universidad de los Andes, Caracas, 1989

GARCÍA, ELOY, El Estado Constitucional ante su $<<$ Momento Maquiavélico>>, Cuadernos Civitas, Madrid, 2000

\footnotetext{
${ }^{13}$ NARANJO MESA, VLADIMIRO, Op. Cit., páginas 124 y 125
} 
GUERRA CURVELO, WEILDER, La Disputa y la Palabra, La ley en la Sociedad Wayuu, Premios Nacionales de Cultura, Ministerio de Cultura, Bogotá, 2002

NARANJO MESA, VLADIMIRO, Teoría constitucional e Instituciones Políticas, Editorial temis, Bogotá, 2003

RAWLS, JOHN, Political Liberalims, Columbia University Press, New York, 1993

SOCIAL SCIENCE RESEARCH NETWORK ELECTRONIC LIBRARY [http://papers.ssrn.com/sol3/papers.cfm?abstract_id=388461]

WASHINGTON UNIVERSITY IN SAINT LOUIS [http://newsinfo.wstl.edu/news/page/normal/638html]

YALE LAW SCHOLL FACULTY

[http://www.law.yale.edu/outside/html/faculty/alc53/profile.html] 